\title{
МОНИТОРИНГ И ПРОГНОЗИРОВАНИЕ КАЧЕСТВА ВОЗДУХА В МОСКОВСКОМ РЕГИОНЕ
}

\author{
Р.М. Вильфанд ${ }^{1}$ И.Н. Кузнецова ${ }^{* *}$, И.Ю. Шалыгина ${ }^{1}$, \\ А.М. Звягинцев ${ }^{2}$, М.И. Нахаев ${ }^{1}$, П.В. Захарова ${ }^{3}$, В.А. Лапченко ${ }^{4}$ \\ ${ }^{1}$ Гидрометцентр России; ${ }^{2}$ Центральная аэрологическая обсерватория; \\ ${ }^{3}$ ГПБУ «Мосэкомониторинг» (Москва, Россия); ${ }^{4}$ Карадагский природный заповедник (Феодосия, Россия) \\ * Эл.nочта:muza@mecom.ru \\ Статья поступила в редакиию 20.10.2014; принята к печати 20.11.2014
}

Сделана оценка и приведены примеры возможностей прогнозирования метеорологических параметров и концентраций загрязняющих воздух веществ, определяющих качество городского воздуха. Приведены общие сведения о загрязняющих городской воздух веществах и их влиянии на здоровье. С использованием данных регулярных наблюдений загрязнения воздуха в Москве рассчитаны сезонная и внутрисуточная изменчивость доминирующих загрязнителей воздуха в мегаполисе. На примере Москвы показана возможность использовать предложенный комплексный метеорологический параметр с тем, чтобы прогнозировать неблагоприятные для очищения воздуха метеорологические условия (НМУ) и повышение уровня загрязнения. Приведены количественные показатели ухудшения качества воздуха в городе летом вследствие повышения повторяемости НМУ и активности фотохимических процессов в городской атмосфере. Обсуждены причины и факторы формирования эпизодов загрязнения с превышением гигиенических нормативов. Отмечено, что эпизоды аэрозольного загрязнения формируются как за счет локальных источников, так и вследствие дальнего переноса, в основном в теплый период. Озоновые эпизоды в Московском регионе наблюдаются чаще всего в июле-августе и возникают в результате фотохимической генерации озона в периоды тихой жаркой и сухой погоды. Показана актуальность и обоснована необхоимость регулярных наблюдений в нашей стране за приземным озоном и твердыми частицами (РМ 10 . Приведены данные о созданной в Гидрометцентре России технологии прогнозирования качества воздуха на основе использования химических транспортных моделей, отмечены проблемы погрешностей модельных расчетов и необходиость их постобработки на этапе освоения численных моделей загрязнения.

Ключевые слова: качество городского воздуха, мониторинг, прогноз, неблагоприятные метеорологические условия, эпизоды загрязнения.

\section{AIR QUALITY MONITORING AND PROGNOSIS IN MOSCOW REGION R.M. Vilfand ${ }^{1}$, I.N. Kuznetsova ${ }^{1 *}$, I.Yu. Shalygina ${ }^{1}$, A.M. Zviagintsev ${ }^{2}$, M.I. Nakhayev ${ }^{1}$, P.V. Zakharova ${ }^{3}$, V.A.Lapchenko ${ }^{4}$ \\ ${ }^{1}$ Hydrometeorological Center of Russia; ${ }^{2}$ Central Aerological Observatory; \\ ${ }^{3}$ Public Institution for Environmental Protection "MosEcoMonitoring" (Moscow, Russia) and \\ ${ }^{4}$ Karagad Natural Reserve (Feodosia, Russia) \\ *E-mail:muza@mecom.ru}

The possibilities to forecast meteorologic parameters and air pollutant levels that determine urban air quality are estimated and exemplified. Basic information about urban air pollutants and their impacts on human health is reviewed. Data derived from regular monitoring of air pollution in Moscow are used to calculate seasonal and diurnal variations in the levels of dominant air pollutants in the megalopolis. An integral meteorologic parameter is suggested for forecasting meteorological conditions unfavorable for depollution of air (MCUDA) and correspondent decreases in air quality as exemplified with Moscow. Quantitative estimates of decreased urban air quality, which occur in summer because of increases in the frequencies of MCUDA episodes and in activities of photochemical processes, are provided. The causes and factors of the episodes of air pollution exceeding hygienic norms are discussed. Such episodes may occur because of local sources of pollutants as well as because pollutants inflow from distant sources, especially in warmer seasons. Ozone outbreaks in Moscow Region are most often detected in July and August because of photochemical generation of ozone during hot and dry weather periods. The necessity and feasibility of regular monitoring of ground air ozone and particulate matter $\left(\mathbf{P M}_{10}\right)$ in Russia is substantiated. The approach to air quality prognosticating based on chemical transport model developed at the Hydrometeorological Center of Russia is outlined. The problems of biases in numerical modelling and of model data postprocessing required at the stage of model implementation are emphasised.

Keywords: urban air quality, monitoring, prognosis, adverse meteorological conditions, pollution outbreaks.

Сегодня в городах проживает примерно три четверти населения России, 90\% населения Европы и половина населения мира [7]. Погодные условия являются важнейшим фактором комфортности городской среды; их влияние на самочувствие человека принято оценивать с помощью целого ряда индексов комфортности погодных условий с использова- нием таких метеорологические характеристик, как температура воздуха, межсуточное изменение температуры и атмосферного давления, среднесуточная относительная влажность, облачность, скорость ветра и др. [35].

Воздушная среда - самая изменчивая по сравнению с другими средами, но и внутри этой неста- 
ционарной системы городская атмосфера является особым мезомасштабным объектом (до десятков километров по горизонтали и до нескольких сотен метров по вертикали) с выраженными отличительными признаками. К их числу относятся: устойчивое формирование городского острова тепла и влаги, изменение радиационного и ветрового режима, облачности и осадков, существенное изменение газоаэрозольного состава атмосферы над городом [2, 8 , $26,30,32,50,56]$. Как следствие, в городской атмосфере наблюдается повышенная химическая активность, способствующая образованию вторичных загрязнений воздуха, часто более токсичных по сравнению с начальными выбросами в атмосферу.

Федеральным законом «Об охране атмосферного воздуха» (№ 96-Ф3 от 4 мая 1999 г.) качество воздуха определено как совокупность физических, химических и биологических свойств атмосферного воздуха, отражающих степень его соответствия гигиеническим и экологическим нормативам качества атмосферного воздуха.

В «Руководящих принципах ВО3 по качеству воздуха» [55] произведена оценка последствий загрязнения воздуха для здоровья и пороговых уровней загрязнения, оказывающих вредное воздействие на здоровье. По последним оценкам ВО3 (Всемирная организация здравоохранения), примерно 7 миллионов случаев преждевременной смерти обусловлено загрязнением атмосферного воздуха (3,7 миллиона) и воздуха внутри помещений (4,3 миллиона). По тем же оценкам, около $80 \%$ случаев преждевременной смерти, связанной с загрязнением атмосферного воздуха, происходят в результате ишемической болезни сердца и инсульта, $14 \%$ - в результате хронической обструктивной болезни легких или острых инфекций нижних дыхательных путей и 6\% - вследствие рака легких [55].

Оценку влияния погодных условий на самочувствие и здоровье на несколько суток вперед обеспечивают расчеты метеорологических характеристик численных моделей атмосферы (www.ras.ru/SciForMed, meteoinfo.ru/forecasts). Оправдываемость метеорологических краткосрочных прогнозов (с заблаговременностью до 3 суток) колеблется на уровне 95\%, среднесрочных (на 3-5 суток) - около 90\%. И, хотя такие показатели достаточно высокие, следует заметить, что стремительно нарастающие мощности вычислительных средств позволят не только повысить надежность прогнозов, но и увеличить пространственную и временную детализацию метеорологических характеристик и явлений погоды, влияющих на самочувствие. Значительный прогресс в этом направлении обеспечивает участие Росгидромета в международном консорциуме COSMO (Consortium for Small-Scale Modeling). Консорциум по мезомасштабному моделированию атмосферы был создан для совместного развития, усовершенствования и поддержки негидростатической региональной атмосферной модели COSMO, которая многократно и детально описана в научных публикациях, размещенных на сайте http://www.cosmo-model.org. Помимо российской стороны, в работе консорциума участвуют метеослужбы Германии, Швейцарии, Италии, Греции, Польши и Румынии. В настоящее время в Росгидромете модель COSMO-RU7 (COnsortium for Smallscale MOdelling - Russia) используется для расчета оперативных прогнозов метеорологических полей и параметров на трое суток по европейской территории России с пространственной детализацией 7 км. С апреля 2011 г. система мезомасштабного прогноза погоды COSMO-RU7 по решению Центральной методической комиссии Росгидромета внедрена в оперативную практику в качестве базовой для численного прогнозирования следующих метеорологических величин: осадки, температура и влажность воздуха, приземный ветер. В ФГБУ «Гидрометцентр России» подготовлена к эксплуатации версия модели, охватывающая всю территорию страны и ближнее зарубежье [4]. Важно, что модель COSMO-RU7 содержит встроенный модуль COSMO-Ru7-ART (Aerosols and Reactive Trace gases) для расчетов концентраций загрязняющих веществ с учетом их переноса и химических преобразований $[53,31,34]$.

\section{Основные загрязнители воздуха, их воздействие на здоровье}

«Руководящие принципы ВОЗ по качеству воздуха» 2005 г. [55] являются глобальным руководством в отношении пороговых значений и максимально допустимых уровней основных загрязнителей воздуха, представляющих риск для здоровья. Применяемые во всем мире, они основаны на экспертной оценке имеющихся научных данных в отношении: твердых частиц (ТЧ, англоязычный термин - Particulate Matter, $\mathrm{PM})$; озона $\left(\mathrm{O}_{3}\right)$; двуокиси азота $\left(\mathrm{NO}_{2}\right)$ и двуокиси серы $\left(\mathrm{SO}_{2}\right)$. Кратко охарактеризуем основные вещества и факторы, ухудшающие качество воздуха.

Наиболее разрушительны для здоровья взвешенные частицы диаметром 10 микрон и менее (РМ 10 ), поскольку такие частицы проникают глубоко в легкие и осаждаются там. Они состоят из сложной смеси крупных и мелких твердых и жидких частиц как неорганических, так органических веществ, присутствующих во взвешенном состоянии в воздухе. Границей между двумя фракциями обычно служат частицы с диаметром в 2,5 мкм $\left(\mathrm{PM}_{2,5}\right)$.

Крупные частицы (размером более 2,5 мкм) образуются в результате механического распада твердых частиц и поступают в атмосферу в результате ветровой эрозии, пыления грунтовых дорог и от стирания покрышек автотранспорта, а также в результате испарения морских брызг ${ }^{1}$ В составе $\mathrm{PM}_{10}$ могут находиться первичные биологические аэрозольные частицы: пыльца растений, грибковые споры, бактерии и вирусы, некоторые из них являются аллергенами [41]. Пыльца, споры плесени, а также растений и насекомых относятся к крупной фракции; более мелкие частицы в значительной степени формируются из газов путем коагуляции и конденсации.

Длительное воздействие твердых частиц усугубляет риск развития сердечно-сосудистых и респираторных заболеваний, а также рака легких [55]. Частицы $\mathrm{PM}_{10}$ воздействуют на большее число людей, чем какой-либо другой загрязнитель воздуха. Загрязнение воздуха некоторыми твердыми частицами оказывает воздействие на здоровье даже при очень низких уровнях. До сих пор не установлено пороговое значение, ниже которого вред для здоровья не наблюдается.

Качество воздуха обычно оценивается в суточных или годовых концентрациях; по данным [55],

${ }^{1}$ От редакции: см. статью Семина с соавт. в этом номере журнала «Биосфера». 
предельный среднегодовой уровень $\mathrm{PM}_{10}$ составляет

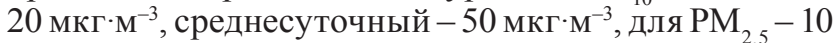
и 25 мкг' $\mathrm{M}^{-3}$ соответственно. Отечественный средне-

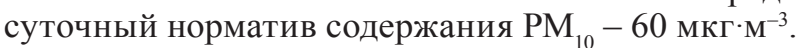

Серьезный риск для здоровья создают не только твердые частицы, но и озон, двуокись азота (NO,) и двуокись серы. Озон является одним из основных факторов риска заболеваемости и смертности от астмы, в то время как двуокись азота и двуокись серы могут быть причастными к развитию астмы, бронхиальных симптомов, воспаления легких и к снижению функции легких В настоящее время озон является главным, вызывающим наибольшее беспокойство, загрязнителем воздуха в США и вторым, после твердых частиц, в Европе [42, 46]. Кроме влияния на здоровье, повышенные уровни озона значительно уменьшают урожайность сельскохозяйственных культур и отрицательно воздействуют на рост деревьев $[40,47]$. В США стоимость ежегодных потерь урожая из-за воздействия озона оценивается в сумму около 3 млрд долларов, а в Индии потери урожая таковы, что ими можно было бы накормить 94 млн человек [45].

Для усредненной за 8 часов приземной концентрации озона рекомендуется предельный уровень 100 мкг $\mathrm{M}^{-3}$ [55]; российскими нормативами определен предельный уровень в среднем за сутки 30 мкг $\mathrm{M}^{-3}$ и максимальный

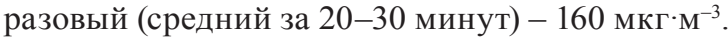

Озон на уровне земной поверхности (не путать с озоновым слоем в верхних слоях атмосферы!) является основным компонентом фотохимического смога. Он образуется под воздействием солнечного света в фотохимических реакциях таких загрязнителей, как окислы азота $\left(\mathrm{NO}_{x}\right)$ и летучие органические соединения (ЛОС), выделяемых транспортными средствами, растворителями и промышленностью.

Основными источниками антропогенного образования $\mathrm{NO}_{2}$ являются процессы сжигания (обогрев, выработка электроэнергии, работа двигателей машин и судов). $\mathrm{NO}_{2}$ является основным источником нитратных аэрозолей, образующих одну из основных фракций $\mathrm{PM}_{2,5}$, а под действием ультрафиолетового света - озон. Как загрязнитель воздуха $\mathrm{NO}_{2}$ воздействует несколькими взаимосвязанными путями: при кратковременном превышении уровня 200 мкг $\mathrm{M}^{-3}$ двуокись азота является токсичным газом, вызывающим сильное воспаление дыхательных путей. Снижение функции легких также связывают с воздействием $\mathrm{NO}_{2}$ при уровнях, регистрируемых (или наблюдаемых) в настоящее время в городах Европы и Северной Америки.

Для $\mathrm{NO}_{2}$ рекомендуется среднегодовой уровень

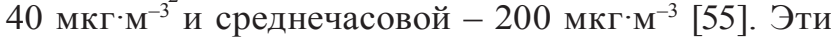
нормативы применяются и в нашей стране.

\section{Наблюдения за качеством воздуха}

Метеорологические показатели качества воздуха оцениваются по данным наземной и аэрологической сети Росгидромета. Появление новых технических средств, к числу которых относятся получившие распространение в последнее десятилетие микроволновые измерители профилей температуры - профилемеры МТП-5 (http://mtp5.ru/), позволяют получать информацию о вертикальной структуре температурного поля нижней атмосферы и с высокой точностью диагностировать термическую устойчивость, которая является одним из важнейших регуляторов переноса примесей в атмосфере. Наблюдения в ниж- них слоях атмосферы представляют особый интерес в связи с увеличением высотности застройки и, тем самым, увеличением слоя атмосферы, важного для жизнедеятельности горожан. Уникальные данные измерений на телебашне Останкино в Москве дают возможность фиксировать и изучать явления внутри пограничного слоя атмосферы, оказывающие прямое и значительное влияние на рассеивание загрязняющих веществ: низкоуровневые струйные течения, эволюцию слоя перемешивания, синоптически зависимую динамику температурной инверсии и пр.

Регулярные наблюдения за содержанием загрязняющих веществ в воздухе городов и промышленных агломераций, а также на фоновых территориях проводятся в нашей стране на сети Росгидромета более 50 лет (http://www.meteorf.ru/upload/). В двух российских мегаполисах - Москве и Санкт-Петербурге функционируют сети автоматизированных измерений концентраций загрязняющих веществ, аналоги зарубежных систем мониторинга. В Московском регионе сеть мониторинга интенсивно наращивается; сегодня число станций ГПБУ «Мосэкомониторинг» превышает 40, в числе контролируемых ими примесей - $\mathrm{PM}_{10}$ и $\mathrm{O}_{3}$. Данные измерений в режиме реального времени представляются на веб-сайте (http://www mosecom.ru); здесь же можно видеть результаты измерений концентраций некоторых примесей на трех уровнях телебашни Останкино (до высоты 350 м).

Важной составляющей системы мониторинга является прогнозирование метеорологических условий и загрязнения воздуха с приоритетной задачей заблаговременного предупреждения о неблагоприятных метеорологических условиях (НМУ), сопровождающихся увеличением загрязнения городского воздуха и достижением опасных уровней. НМУ являются обоснованием для проведения природозащитных мероприятий предприятиями, дающими основной вклад в загрязнение городского воздуха.

\section{Характерные особенности загрязняющих веществ и их связей с метеорологическими условиями}

Содержание антропогенных примесей в приземном слое городской атмосферы, изначально определяемое эмиссиями загрязняющих веществ, зависит от условий для их рассеивания в атмосфере. От атмосферных условий зависит и интенсивность образования вторичных загрязнений, и возможность переноса загрязнений из удаленных районов. Многие загрязнения (формальдегид, фенол, озон и т. п.) показывают выраженную сезонную зависимость $[6,9,44]$.

C учетом генезиса и факторов короткопериодных флуктуаций концентраций загрязняющие вещества можно условно разделить на три группы: первичные и короткоживущие $(\mathrm{CO}, \mathrm{NO})$, зависимые от фотохимического производства $\left(\mathrm{O}_{3}\right)$ и аэрозольное загрязнение $\left(\mathrm{PM}_{10}\right)$. Наши исследования показали, что в диапазоне высоких концентраций каждая из групп загрязнений имеет характерные и специфические связи с локальными метеорологическими условиями и крупномасштабными атмосферными процессами $[1,10,12,25,26,50]$. При этом важно отметить, что в целом (в динамическом диапазоне концентраций) связи между отдельными группами веществ достаточно высокие; так $\mathrm{CO}$ и $\mathrm{PM}_{10}$ имеют высокую корреляцию $\mathrm{R} \approx 0,8[6]$. 
Приведенные на рис. 1 типовые суточные ходы концентрации загрязнений $\mathrm{CO}, \mathrm{O}_{3}, \mathrm{NO}$ и $\mathrm{NO}_{2}$ иллюстрируют различия в холодный и теплый сезоны. Внутрисуточные пиковые концентрации веществ первой группы загрязнений (СО и др.) приходятся на утренние и вечерние часы - время максимального трафика и ослабленного перемешивания. (Иной тип суточного хода озона, он будет обсуждаться в следующем разделе.)

Устойчивое образование внутрисуточных экстремумов концентраций (вследствие особенностей как суточного хода метеопараметров, так и цикличности выбросов загрязнений в атмосферу) служит основанием для того, чтобы выделить в режиме городских загрязнений четыре внутрисуточных интервала (условно ночь, утро, день и вечер), каждый из которых содержит главный или вторичный максимум или минимум. Такой подход позволяет эффективнее оценивать влияние метеорологических условий на колебания уровня загрязнения, в частности, на формирование максимальных концентраций по периоду. В табл. 1 представлены рассчитанные коэффициенты корреляции между максимальными внутри 6-часовых интервалов концентрациями первичных загрязняющих веществ (CO, NO) и образующегося $\mathrm{NO}_{2}$ (число случаев в холодный, теплый периоды и год в целом составили 212, 153 и 365 соответственно, $\mathrm{p}<0,05)$. Видно, что наиболее тесные связи наблюдаются между первичными загрязнениями $(\mathbf{C O} \mathbf{N O})$ в течение суток и в целом за год, и в отдельные сезоны. Обращает на себя внимание общее ослабление связей в теплый сезон, когда повышается химическая активность атмосферы, и характерное уменьшение коэффициентов корреляции между пиковыми концентрациями загрязнений в вечернее время.

При всем многообразии зависимостей и связей загрязняющих веществ с метеорологическими условиями, с позиций прогнозирования НМУ важно установить наиболее «чувствительные» маркеры загрязнения городского воздуха. Одним из главных вы- водов, следующих из приведенных в табл. 1 расчетов, является заключение об обоснованности использования концентрации СО в качестве маркера общего загрязнения воздуха, в частности, для анализа воздействия атмосферных процессов на изменчивость воздушного загрязнения первичных и короткоживущих вторичных загрязнений.

Для этой группы веществ разработана типизация метеорологических условий загрязнения воздуха, прошедшая калибровку на данных мониторинга загрязнений воздуха в Москве в полном диапазоне атмосферных процессов [28]. Установлены комплексы характеристик атмосферных процессов и локальных метеорологических условий, способствующие:

- накоплению вредных примесей и повышению уровня загрязнения до критических величин (неблагоприятные метеорологические условия - НМУ);

- умеренному очищению воздуха с преобладающим характерным сезонным уровнем загрязнения и возможностью кратковременного повышения уровня загрязнения вблизи источников выбросов (в основном в районах, прилегающих к автодорогам с высокой транспортной нагрузкой);

- интенсивному рассеиванию примесей или удалению их осадками с пониженным содержанием антропогенных загрязнений в приземном воздухе.

В целом ряде публикаций $[16,17,33,38]$ показано, что связи загрязнения с комплексом метеорологических условий теснее, чем с отдельными метеорологическими характеристиками. Был предложен комплексный метеорологический параметр загрязнения (МПЗ), рассчитываемый на основании данных (или прогноза) средней скорости переноса в атмосферном пограничном слое, вертикального градиента температуры, количества осадков. Выполнена количественная идентификация полного ряда атмосферных процессов, влияющих на загрязнение воздуха, что позволило выделить 11 подтипов МПЗ (подробно описано в [28]). Тестирование на соответствие МПЗ концентрациям отдельных загрязняющих веществ

Коэффициенты корреляции усредненных по станциям города максимальных концентраций СO, NO и NO. Москва, 2011 г.

\begin{tabular}{|c|c|c|c|c|c|c|c|c|c|c|c|c|}
\hline \multirow{2}{*}{ Период } & \multicolumn{4}{|c|}{$\mathrm{CO} \leftrightarrow \mathrm{NO}$} & \multicolumn{4}{|c|}{$\mathbf{N O} \leftrightarrow \mathrm{NO}_{2}$} & \multicolumn{4}{|c|}{$\mathrm{CO} \leftrightarrow \mathrm{NO}$} \\
\hline & Ночь & Утро & День & Вечер & Ночь & Утро & День & Вечер & Ночь & Утро & День & Вечер \\
\hline Холодный & 0,93 & 0,95 & 0,94 & 0,94 & 0,73 & 0,8 & 0,83 & 0,66 & 0,8 & 0,85 & 0,86 & 0,72 \\
\hline Теплый & 0,91 & 0,93 & 0,83 & 0,89 & 0,6 & 0,68 & 0,62 & 0,46 & 0,66 & 0,72 & 0,83 & 0,62 \\
\hline Год & 0,92 & 0,94 & 0,9 & 0,9 & 0,66 & 0,73 & 0,77 & 0,56 & 0,7 & 0,78 & 0,85 & 0,67 \\
\hline
\end{tabular}
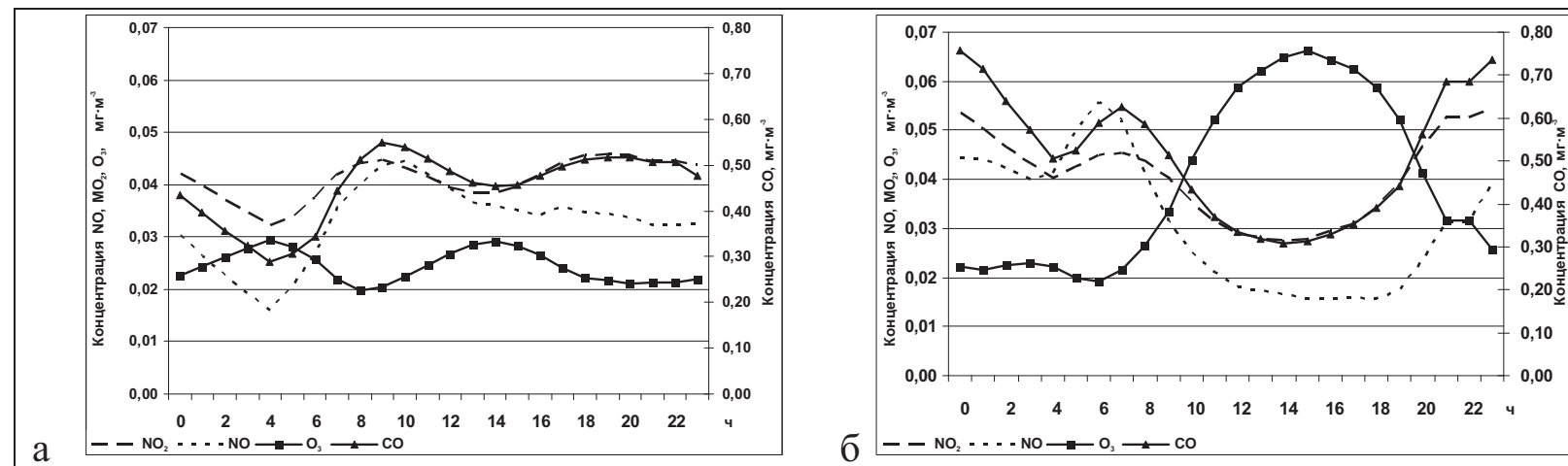

Рис. 1. Типовые усредненные суточные изменения концентраций $\mathrm{CO}, \mathrm{NO}, \mathrm{NO}_{2}$ и $\mathrm{O}_{3}\left(\mathrm{Mr}^{\circ} \mathrm{M}^{-3}\right.$ ) в холодный (а) и теплый (б) сезоны 2011 г. по данным наблюдений на станциях мониторинга Москвы (http://www.mosecom.ru) 
показало целесообразность выделения более крупных градаций - трех типов МПЗ. На рис. 2 показаны распределения концентрации СО (маркера общего городского загрязнения) для каждого типа МПЗ.

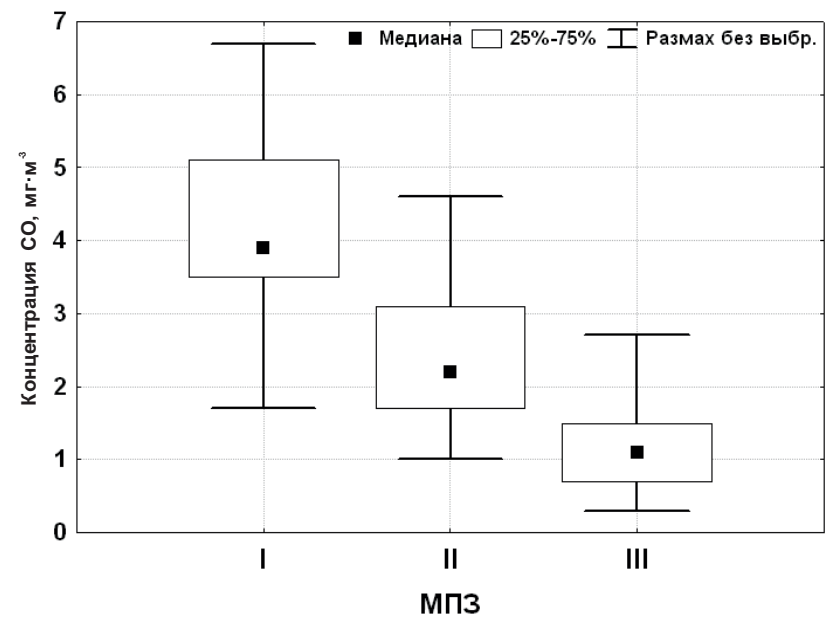

Рис. 2. Соответствие типов МПЗ диапазонам максимальной усредненной по городским станциям концентрации СО $\left(\right.$ мг $\left.^{-3}\right)$

Отметим, что МПЗ(I) представляет наиболее неблагоприятные для очищения городского воздуха метеорологические процессы (НМУ) - первый тип атмосферных процессов. МПЗ(I) идентифицируется в случаях образования температурной инверсии в сочетании со слабым переносом в нижнем слое атмосферы при отсутствии осадков. Как показало тестирование на многолетних рядах данных, только в таком сочетании метеорологических параметров наблюдается увеличение загрязнения приземного воздуха на большей части мегаполиса до опасных уровней. В отсутствии одного из названных факторов возможно повышение уровня, но критических величин концентрации загрязняющих веществ не достигают [21, 25], за исключением ситуаций, связанных с адвекцией загрязняющих веществ из районов лесных пожаров, как это имело место летом в аномально сухом и жарком 2010 г. [13, 18, 23, 25, 36].

МПЗ(III) представляет группу атмосферных процессов, обеспечивающих очищение городского воздуха от загрязняющих веществ: а) благодаря интенсивному переносу воздушных масс в нижней атмосфере; б) через механизм турбулентного перемешивания при наличии струйных течений нижних уровней; в) за счет рассеивания под воздействием дневной конвекции; г) за счет выпадения с осадками в зоне атмосферных фронтов или в центре малоподвижных циклонов; д) при резкой смене воздушных масс в отсутствие явных признаков прохождения атмосферного фронта (облачности, осадков, усиления ветра).

МПЗ(II) определяется атмосферными процессами с умеренной скоростью переноса воздушных масс и выраженным направлением ветра, при этом не исключены небольшие локальные осадки. При ослаблении вертикального перемешивания в отсутствии осадков перенос в атмосферном пограничном слое (АПС) со скоростью не более 6-7 $\mathrm{M}^{-1} \mathrm{c}^{-1}$ может оказаться благоприятным для локального повышения уровней загрязнения в подветренной части мегаполиса $[21,25]$.

Рис. 2 иллюстрирует связь между МПЗ и усредненной по городским станциям максимальной кон- центрации СО (утро). Полное соответствие уровня загрязнения определенному типу атмосферных условий (МПЗ) не наблюдается в силу влияния многих факторов, в том числе - непостоянства объема выбросов, эффекта выходного дня [10], сезонно зависимой интенсивности образования вторичных продуктов загрязнения [12], дефицита данных о процессах в пограничном атмосферном слое, например, о воздействии примесей низкоуровневых струйных течений на рассеивание [48], и др.

С позиций идентификации и заблаговременного предсказания наступления экологически неблагоприятных погодных условий и опасных уровней загрязнения проведен анализ сезонного распределения и внутрисуточных особенностей формирования НМУ в Московском мегаполисе. Установлено, что частота НМУ имеет выраженную сезонную и внутрисуточную доминанту (рис. $3 a$ ): чаще всего НМУ наблюдаются летом (около 50\% от общего числа НМУ) и весной (около 25\%).

Крайне редко НМУ в Москве наблюдаются в ноябре и декабре; годовой максимум количества НМУ приходится на июль-август, вторичный максимум на апрель (рис. 3б, в). В соответствие с сезонными особенностями метеорологических параметров, формирующих НМУ, в отдельные месяцы наблюдается внутрисуточное смещение числа НМУ: в июле НМУ наблюдаются чаще всего ночью и утром, в другие месяцы годовых максимумов НМУ (август, апрель) различия в частоте НМУ (вечером, ночью и утром) незначительны. По приведенным данным можно заметить, что аномальная крупномасштабная циркуляция и погодные условия летом 2010 г. $[23,36]$ внесли весомый вклад в статистику, повысив сумму календарных дней с НМУ в июле и августе на 10 и 15 соответственно.

В целом за год НМУ для первой группы загрязнений чаще наблюдаются ночью, исключительно редко - днем. Иной характер имеет распределение метеорологических условий, способствующих образованию высоких уровней приземного озона.

\section{Озоновое загрязнение в Московском регионе}

Атмосферный озон постоянно образуется в стратосфере под действием ультрафиолетового излучения Солнца с длиной волны $\lambda<242$ нм; одновременно на всех высотах под действием излучения в УФ и видимой области спектра происходит и разрушение озона. Самое большое в атмосфере отношение числа молекул озона к общему числу молекул в единице объема («отношение смеси озона») - около 10 на 1 миллион - имеет место в области высот 30- 50 км, ниже которой ультрафиолетовое излучение с длиной волны $\lambda<240$ нм практически не проникает. Наполнение озоном нижних слоев атмосферы происходит путем турбулентного перемешивания: из стратосферы в тропосферу озон проникает за счет так называемого стратосферно-тропосферного обмена, который в последнее время является предметом интенсивного изучения. Озон образуется и в самой тропосфере под действием ультрафиолетового солнечного излучения в реакциях с участием оксидов азота $\left(\mathrm{NO}_{x}=\mathrm{NO}+\mathrm{NO}_{2}\right)$ и летучих неметановых углеводородов, метана $\left(\mathrm{CH}_{4}\right)$ и моноксида углерода $(\mathrm{CO})$ $[3,52]$. Оксиды азота в этих реакциях выступают в 


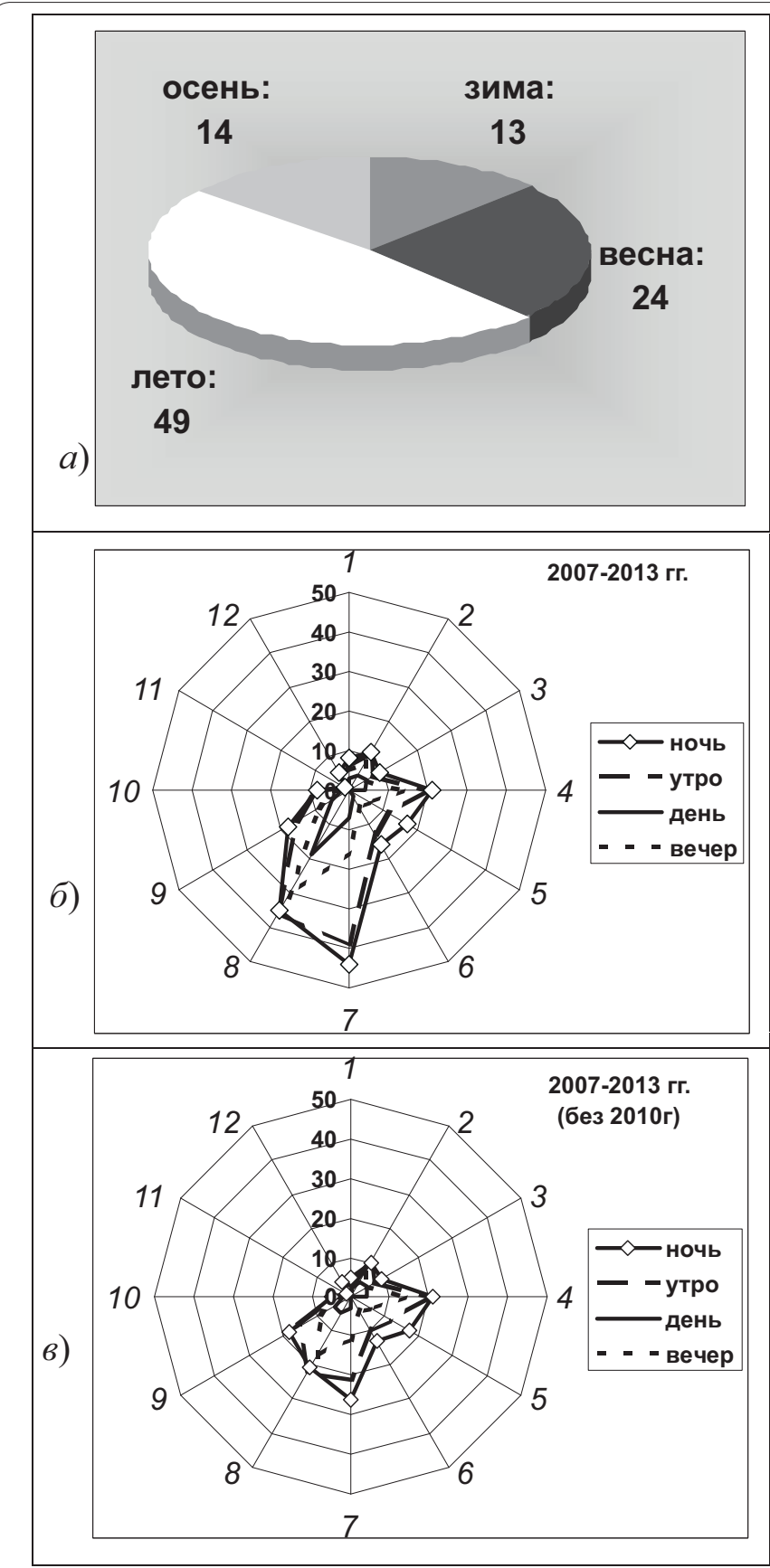

Рис. 3. Сезонно-суточное распределение НMУ в Московском регионе:

a) сезонная повторяемость НМУ (\%);

б) число наблюдавшихся в различные временные интервалы НМУ по месяцам в 2007-2013 гг.;

в) то же, что в (б), с исключением данных аномального по погодным условиям 2010 г.;

На рис. $(6$, в) расстояние от центра - число случаев, радиальные направляющие - месяца года

качестве катализаторов, то есть в процессе реакций практически не расходуются; расходуются только углеводороды. Если оксиды азота являются продуктами антропогенной деятельности, то углеводороды могут иметь как естественное, так и антропогенное происхождение. Поверхность Земли является для озона стоком. Скорость разрушения озона зависит от типа поверхности: например, на морской и заснеженной поверхности разрушение много меньше, чем на травяной. Баланс озона в тропосфере рассчиты- вается в моделях, которые дают качественно одинаковые, но количественно несколько различающиеся результаты $[54,57]$. Общим практически для всех моделей является то, что масса озона, поступившего из стратосферы за счет стратосферно-тропосферного обмена, заметно меньше, чем массы фотохимически образованного и фотохимически разрушенного в тропосфере озона в отдельности, однако значительно больше (в разы), чем их алгебраическая сумма.

На верхней границе пограничного слоя атмосферы (около 1,5 км) отношение смеси озона обычно составляет 0,04-0,05 млн ${ }^{-1}$. В течение суток оно практически не меняется, наблюдаются лишь небольшие сезонные изменения. Следует подчеркнуть, что в основном содержание озона в приземном воздухе определяется его поступлением из вышележащих слоев тропосферы. Различные типы сезонного и суточного хода приземного озона на фоновых станциях подробно обсуждаются $[15,51]$. На равнинных фоновых станциях суточный максимум приземного озона обычно наблюдается через 2-4 часа после местного полудня, а сезонный - весной или летом. Такая же, хотя и несколько более сложная картина наблюдается и в мегаполисах $[12,44]$. На рис. 4 приведены средние суточные ходы концентрации приземного озона (у земли концентрация озона практически точно равна удвоенному значению его отношения смеси) на московской станции МГУ и, для сравнения, на станции фонового мониторинга в Карадагском природном заповеднике в Крыму [29] в различные сезоны.

Наблюдаемые закономерности суточного и сезонного хода приземного озона качественно могут быть объяснены динамикой пограничного слоя атмосферы. На поверхности Земли озон разрушается; поэтому в ночное время при отсутствии вертикального перемешивания концентрация приземного озона со временем уменьшается. Именно такая ситуация наблюдается, когда образуется инверсия температуры, затрудняющая вертикальное перемешивание. После восхода Солнца температурная инверсия исчезает, начинается интенсивное вертикальное перемешивание, и концентрация приземного озона в отсутствие приземных источников озона приближается к наблюдаемой на верхней границе слоя перемешивания (в свободной тропосфере). В холодное время года вертикальное перемешивание слабее, в теплое интенсивнее и охватывает больший слой атмосферы, поэтому сезонный минимум приземного озона наблюдается в холодное время года. Как видно на рис. 4, внутрисуточная динамика озона в мегаполисе отличается от сельской местности хорошо выраженной амплитудой.

В теплый сезон временами отмечается рост концентрации (отношения смеси) приземного озона до 100 млрд $^{-1}$ и выше. Впервые такие случаи были зарегистрированы в 1940-х гг. в Лос-Анджелесе в сочетании с сильной дымкой, а само явление получило название смога Лос-Анджелесского (фотохимического) типа. В результате исследований, в первую очередь, А.Дж. Хаагена-Смита, была установлена возможность, при определенных условиях, интенсивного фотохимического образования озона в тропосфере [43]. Такие условия часто возникают в малоподвижных воздушных массах при неблагоприятных для рассеивания загрязнений метеорологических условиях и повышении приземной температуры воздуха 

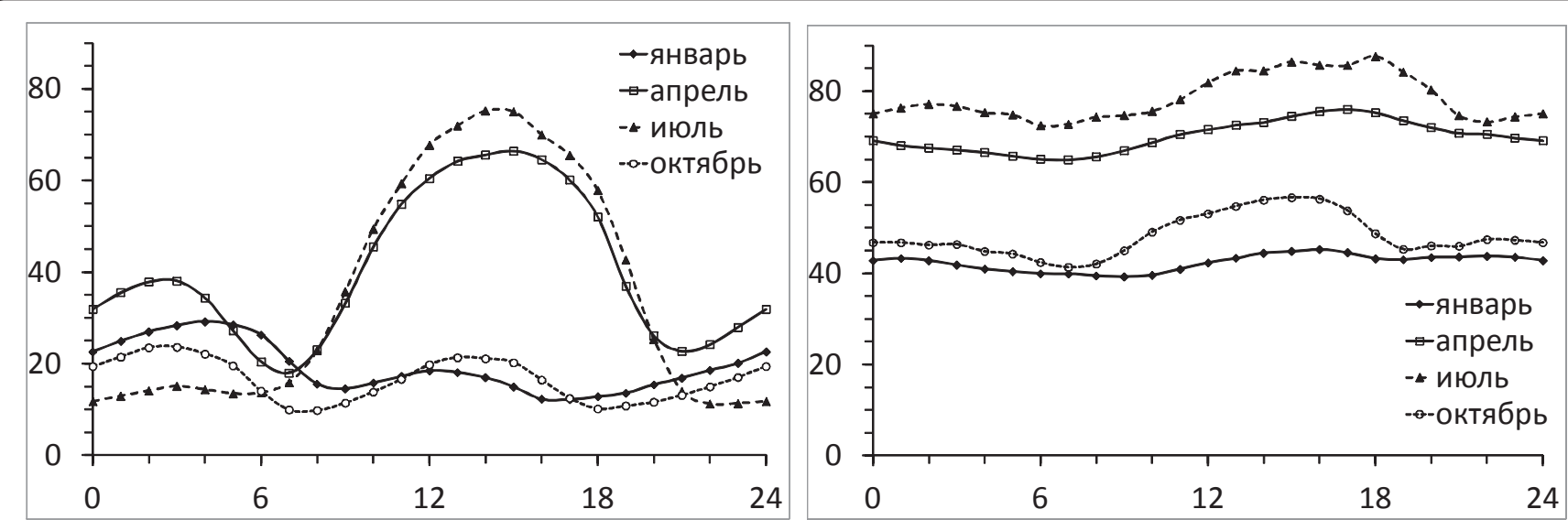

Рис. 4. Средний многолетний суточный ход концентрации озона, мкг-'3, в Москве (слева) и на станции Карадаг в Крыму (справа) в различные месяцы

выше $27^{\circ} \mathrm{C}[16,38]$. В условиях Московского региона наиболее интенсивные эпизоды с опасными для здоровья уровнями озона наблюдались при лесных и торфяных пожарах. Так, летом 2010 г. зафиксировано повышение приземного озона до 150-200 млрд ${ }^{-1}$; что превысило уровни озона, когда-либо зарегистрированные в Европе $[18,39]$. У черноморского побережья на территории Карадагского заповедника в Крыму, где антропогенных выбросов в атмосферу практически нет, отношения смеси озона в жаркий сезон могут достигать 90-100 млрд ${ }^{-1}$ [29], но не более; сюда озон приносится издалека либо образуется в фотохимических реакциях с участием углеводородов, выделяемых растительностью.

В Московском регионе события с нарушением отечественного гигиенического норматива

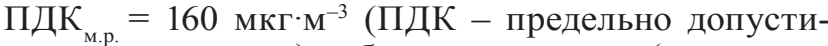
мая концентрация) наблюдаются редко (как правило, 1-3 раза в летние месяцы) и не каждый год. Но, как показывают наши расчеты, ситуации с превышением рекомендованных ВОЗ критериев [55], а именно, максимальной за сутки усредненной за 8 часов концентрации озона (ранее 120, в настоящее время

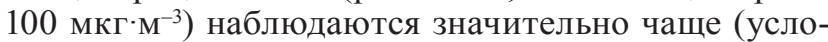
вимся называть такие явления «озоновые эпизоды»). В табл. 2 приведены данные для станции городского типа (Марьинский парк), они представляют усредненную по городу картину (следует отметить, что число озоновых эпизодов в окрестностях мегаполиса несколько больше).

Число календарных дней с концентрациями приземного озона более 160, 120 и 100 мкг $\mathbf{M}^{-3}$. Москва, ст. Марьинский парк. 2008-2013 гг. (общее число дней 2106)

\begin{tabular}{|l|c|c|c|}
\hline Месяц & $\geq \mathbf{1 6 0}$ & $\mathbf{\geq 1 2 0}$ & $\geq \mathbf{1 0 0}$ \\
\hline Март & & 1 & 9 \\
\hline Апрель & & 5 & 26 \\
\hline Май & & 4 & 34 \\
\hline Июнь & 1 & 4 & 16 \\
\hline Июль & 5 & 19 & 50 \\
\hline Август & 2 & 6 & 31 \\
\hline
\end{tabular}

Обращает внимание, что наиболее часто озоновые эпизоды с нарушением всех критериев опасности наблюдаются в июле, а также в августе, что обусловлено, в первую очередь, увеличением повторяемости НМУ в эти месяцы (рис. 3) и свидетельствует об участии «антропогенного» озона в ухудшении качества воздуха летом. Имеющий место относительный минимум в июне является отражением влияния погодных условий на фотохимический рост озона. Благоприятные для этого условия (периоды сухой солнечной и жаркой погоды) в регионе формируются редко. Также можно заметить, что в рассмотренном шестилетнем ряду действующий

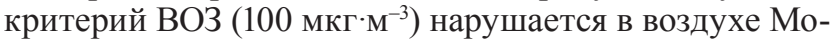
сквы в апреле примерно 4-6 раз. Но такие события, как правило, не связаны с фотохимической наработкой озона в загрязненном городском воздухе, а обусловлены поступлением озона из свободной тропосферы [37]. Отметим, что именно в апреле, как показали наши расчеты [26], формируются самые большие в году вертикальные градиенты температуры в нижней атмосфере, указывающие на процессы интенсивного вертикального обмена. В марте единичные случаи превышения максимальной за сутки усредненной за 8 часов концентрации озона 100 мкг ${ }^{-3}{ }^{-3}$ в основном связаны с событиями субстратосферного вторжения в тылу циклона после прохождения холодного атмосферного фронта.

Пример Лос-Анджелеса показывает, что с опасными для здоровья уровнями озона можно бороться, ужесточая требования к выбросам загрязнений в атмосферу и тем самым уменьшая их объемы [49]. Одним из путей ослабления последствий влияния высоких концентраций озона является широкое информирование о наступлении таких условий. Для расчетов максимальных концентраций приземного озона разработан статистический метод прогноза, опирающийся, в основном, на прогнозы метеопараметров и данные наблюдений приземного озона в предшествующие дни [17]. Примеры сравнения результатов статистического прогноза с модельным прогнозом в период июль-август 2010 г. представлены на рис. 5. Для сравнений были использованы прогнозы максимальной концентрации приземного озона в Москве по расчетам химической транспортной модели EURAD, разработанной в Кельнском университете. Прогнозы EURAD находятся в открытом доступе на веб-сайте (http://www.eurad.uni-koeln.de). 


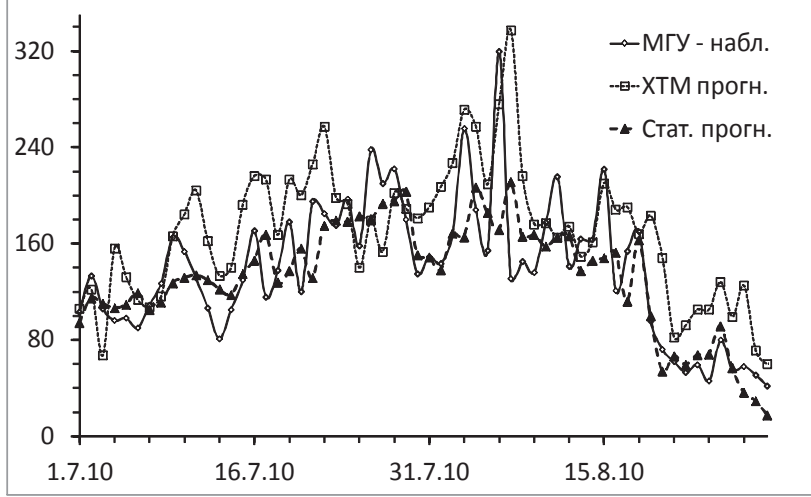

Рис. 5. Максимальные суточные концентрации приземного

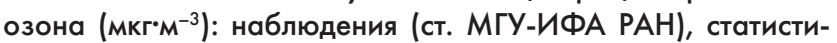
ческий и модельный прогноз EURAD. Июль-август 2010 г.

Из рис. 5 видно, что в период, когда максимальные суточные концентрации приземного озона не превышают предельно допустимых максимальных разовых, качество статистического прогноза является удовлетворительным и выше качества прогноза с использованием XTM EURAD. При превышении предельно допустимых максимальных разовых концентраций приземного озона оба метода прогнозирования дают значения выше критических уровней, однако относительные погрешности обоих прогнозов заметно возрастают.

Имеющиеся модельные и методические погрешности прогноза приземного озона указывают на необходимость их усовершенствования, в частности, разработки комбинированных методов с учетом особенностей каждого из них.

\section{Особенности загрязнения воздуха мелкодисперсным аэрозолем размером менее 10 мкм}

Содержание взвешенных частиц размером менее 10 мкм $\left(\mathrm{PM}_{10}\right)$ по рекомендациям ВО3 является приоритетным в оценке качества воздуха [5]. В развитых странах мониторинг $\mathrm{PM}_{10}$ осуществляется на густой сети станций: по данным ЕРА (Environmental Protection Agency), на территории США - 740 станций (http://www.epa.gov), в Германии - около 270, во Франции - около 400 (http://acm.eionet.europa.eu/). В нашей стране регулярные наблюдения за $\mathrm{PM}_{10}$ и $\mathrm{PM}_{2,5}$ пока проводятся только в двух самых крупных мегаполисах страны, наиболее продолжительные ряды наблюдений - в Московском регионе (http://mosecom.ru).

Сравнение содержания $\mathrm{PM}_{10}$ в воздухе Москвы с другими мегаполисами приводится на рис. 6. Как видно, средняя годовая массовая концентрация $\mathrm{PM}_{10}$ в Москве мало отличается от таковой в Лондоне, но ее величина, например, в отличие от Парижа, превы-

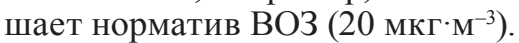

Некоторые характеристики изменчивости содержания $\mathrm{PM}_{10}$ в Московском регионе и обобщения причин и факторов короткопериодных флуктуаций приведены в ряде публикаций $[9,11,24,27,44]$. Здесь рассмотрим особенности годового и внутрисуточного содержания $\mathrm{PM}_{10}$ с позиций зависимости от метеорологических факторов. Отметим, что из представлен-

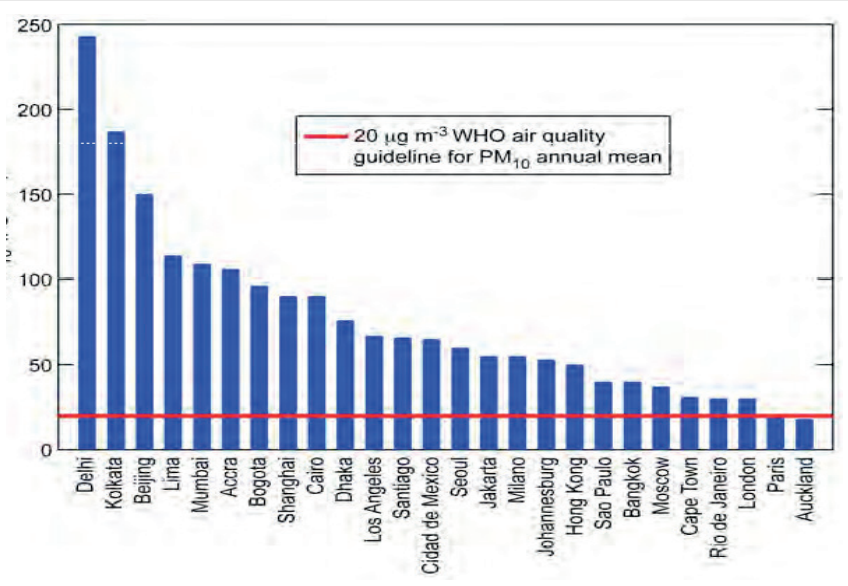

Pис. 6. Сравнение средней годовой концентрации $\mathrm{PM}_{10}$ между 26 крупнейшими городами мира (http://www.wmo. int/pages/prog/arep/gaw/documents/Final_GAW_205_ web_31_January.pdf)

ных данных исключены наблюдения аномального по погодным условиям и режиму загрязнения воздуха августа 2010 г.; им посвящены многие работы, в частности, серия статей в [23].

На рис. 7 представлен сезонно-суточный ход $\mathrm{PM}_{10}$, усредненный по данным наблюдений в 2008-2013 гг. на станции городского типа МГУ. Эта иллюстрация отражает общие закономерности изменчивости $\mathrm{PM}_{10}$ в городском воздухе, а именно, увеличение содержания взвешенных мелких частиц в теплый период (апрельсентябрь) в сравнении с зимним сезоном в среднем на

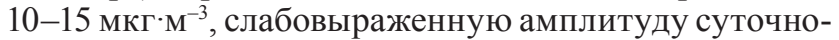
го хода зимой по сравнению с теплым сезоном. Также имеют место сезонные различия времени формирования экстремумов $\mathrm{PM}_{10}$ : суточный максимум наблюдается летом утром и вечером, зимой - днем; суточный минимум РМ 10 зимой отмечается ночью, летом самый низкий уровень $\mathrm{PM}_{10}$ наблюдается после полудня, ночью - вторичный минимум.

Указанные сезонные особенности во многом определяются метеорологическими условиями рассеивания примеси, зависящими от термической устойчивости и скорости переноса. Для зимнего режима характерно преобладание умеренных и сильных скоростей переноса на фоне термической устойчивости: образующийся днем слой перемешивания охватывает нижние 200-300 м, что создает условия для некоторого накопления загрязнений в городской

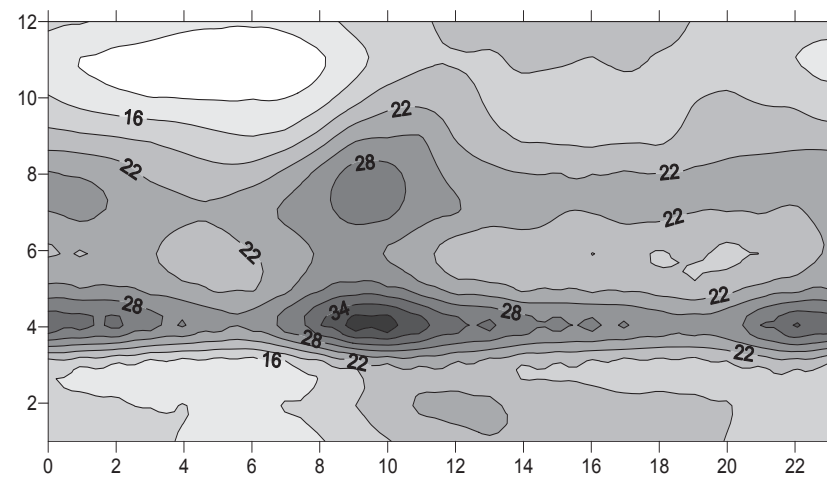

Рис. 7. Сезонно-суточный ход $\mathrm{PM}_{10}$. Москва, 2008-2013 гг. По горизонтальной оси - часы суток, по вертикальной месяцы, начиная с января 
атмосфере. Летом конвективное перемешивание с вышележащим чистым воздухом в слое до 2-3 км служит мощным механизмом очищения приземного воздуха от аэрозолей в дневные часы. Формированию утреннего максимума, как и вторичного вечернего, способствует увеличение повторяемости слабых ветров в сочетании с температурными инверсиями [28]. В летние месяцы в среднем уровень $\mathrm{PM}_{10}$ в Москве низкий и мало отличается от аэрозольного загрязнения в европейских столицах. Несовпадение годовых максимумов в Москве и в европейских столицах, отмеченные в работах $[19,27]$, в значительной мере объясняются различиями в климатических условиях и зависимостью от региональных природных источников, влияющих на состав $\mathrm{PM}_{10}$. В мегаполисах Центральной Европы, а также в Лондоне годовой максимум, наблюдаемый в январе-феврале, в условиях ослабления вертикального перемешивания может формироваться с участием выбросов при сжигании топлива в отопительных системах (как известно, для зарубежной Европы характерен высокий уровень применения угольно-дровяного обогрева), а также регионального переноса аэрозоля над редко заснеженной поверхностью Западной Европы.

Годовой максимум $\mathrm{PM}_{10}$ в Московском регионе формируется после схода снежного покрова и приходится на апрель (рис. 7). Увеличению весеннего аэрозольного загрязнения часто способствует установление антициклонального типа погоды, с характерными для него нисходящими упорядоченными движениями в нижней атмосфере, продолжительными радиационными инверсиями температуры, отсутствием осадков.

Следует подчеркнуть, что весной аэрозольное загрязнение пополняется частицами, полученными из биологических организмов, включая бактерии, грибковые споры, вирусов и фрагменты пыльцы [41] Именно весной «аллергенный» потенциал насыщенной аэрозолем атмосферы повышается за счет взаимодействия его с другими загрязнителями воздуха. Один из ярких эпизодов пыльцевого загрязнения наблюдался в Москве в конце апреля 2012 г., когда город буквально накрыло облако березовой пыльцы; ее концентрация в воздухе тогда превысила норму приблизительно в 20 раз (http:/www.nat-geo.ru/article/).

В общем ряду флуктуаций концентрации $\mathrm{PM}_{10}$ наиболее значимы эпизоды повышения аэрозольного загрязнения с превышением критических уровней. Большая часть таких эпизодов связана с НМУ, установленных для первичных загрязнений (см. выше), то есть определяется местными источниками при ослабленных процессах атмосферного рассеивания. Но, в отличие от загрязнения газовыми малыми составляющими, часть эпизодов аэрозольного загрязнения в Московском регионе формируется вследствие дальнего переноса продуктов горения лесных пожаров, сжигания сухостоя и стерни, а также в результате переноса почвенного аэрозоля из районов, удаленных на многие сотни километров [25]. Последний тип аэрозольного загрязнения чаще всего отмечается в феврале-апреле, в отдельные годы - в октябре-ноябре и обеспечивается в первую очередь атмосферными процессами, благоприятными для транспортировки мелких частиц на большие расстояния. Одним из механизмов дальнего переноса являются мезоструйные течения в нижнем слое (1-2 км) со скоростью до
12-17 м· ${ }^{-1}$, сопровождающиеся инверсией температуры. Такие атмосферные процессы с выносом теплого и запыленного воздуха из низовий Волги и пустынных районов Прикаспия характерны для теплого сектора антициклона в отсутствие осадков. Следует отметить, что аэрозольные эпизоды такого генезиса имеют специфические признаки: внутрисуточные колебания $\mathrm{PM}_{10}$ незначительны, а высокая концентрация сохраняется в течение нескольких суток.

Подробное обсуждение причин изменчивости $\mathrm{PM}_{10}$ и $\mathrm{O}_{3}$ обусловлено, в первую очередь, их свойствами оказывать установленное негативное влияние на здоровье и, соответственно, важностью задачи прогнозирования метеорологических условий и содержания этих загрязнений в приземном воздухе.

\section{Прогнозирование качества воздуха}

Пространственно-временное распределение концентраций загрязняющих веществ определяется взаимосвязанными динамическими, радиационными и химическими процессами в атмосфере, прогнозирование которых обеспечивается применением химических транспортных моделей (XTM). Благодаря стремительному развитию численного моделирования в последние десятилетия сегодня в зарубежных странах применение ХТМ стало обычной практикой для прогнозирования качества воздуха (http://www. chemicalweather.eu/).

Благодаря сотрудничеству Института прикладной физики РАН (Нижний Новгород) и Межуниверситетской лаборатории атмосферных систем (Франция) впервые для российских условий была адаптирована химическая транспортная модель CHIMERE (www. lmd.polytechnique.fr/chimere) [20]. Сегодня прогнозы XTM CHIMERE [14] для центральной части России представляются на сайте Гидрометцентра России (http://meteoinfo.ru/about/frclmuz). На рис. 8 показаны рассчитанные модельные поля концентраций СО и $\mathrm{NO}_{2}$. В последние годы в Гидрометцентре России также создана технология модельных расчетов полей концентраций загрязняющих веществ $\left(\mathrm{PM}_{10}, \mathrm{O}_{3}, \mathrm{NO}_{x}\right.$, $\mathrm{CO}, \mathrm{SO}_{2}$ и др.), еще одна XTM - COSMO-Ru7-ART разрабатывается в рамках международного консорциума COSMO $[4,31,34,53]$.

Успешность прогноза ХТМ в значительной степени зависит от точности задания антропогенных эмиссий в моделях, а также от погрешностей прогноза метеорологических параметров, используемых для расчета переноса и трансформации загрязняющих веществ. С использованием данных метеорологических наблюдений на телебашне Останкино и на высотной метеорологической мачте в Обнинске определены ошибки модельных прогнозов скорости ветра и температуры в нижнем слое атмосферы (до 300-500 м), в частности, установлено: погрешности прогноза ветра уменьшаются с высотой, в среднем они находятся в пределах 1-3 м. ${ }^{-1}$, ситуации со слабыми ветрами предсказываются с высокой надежностью, имеют место сезонные изменения знака ошибок в АПС. Менее успешным по результатам тестирования оказался модельный прогноз типа термической устойчивости. Выявленные характерные ошибки численных моделей являются мотивировкой для усовершенствования параметризаций, которые необходимо учитывать при ожидании НМУ, прогноз которых проводится на основе данных нескольких моделей атмосферы. 


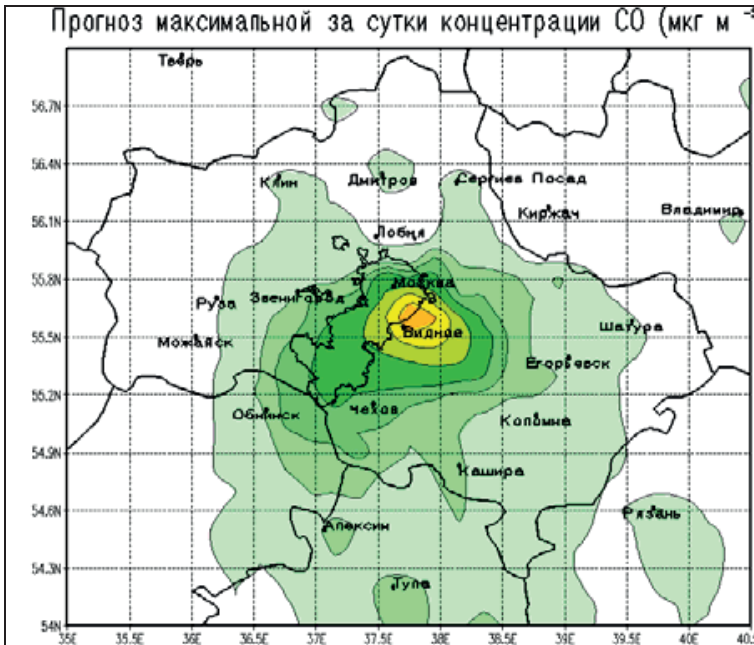

a

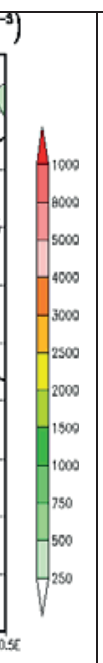

6

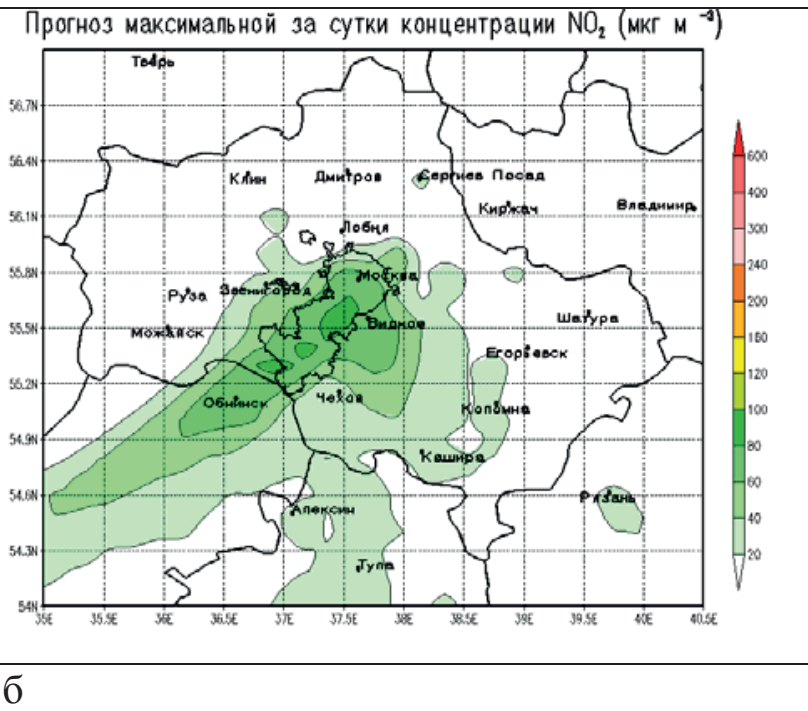

Рис. 8. Примеры прогноза полей максимальных суточных концентраций $\mathrm{CO}, \mathrm{NO}_{2}\left(\right.$ мкг⿱⿰㇒一十凵 $\left.^{-3}\right)$ по XTM Chimere

Верификация модельных расчетов загрязняющих городской воздух веществ $\left(\mathrm{NO}_{x}, \mathrm{CO}, \mathrm{O}_{3}\right.$ и $\left.\mathrm{PM}_{10}\right)$ на данных непрерывных измерений концентраций в Московском регионе также служит одним из способов совершенствования численных расчетов полей концентраций, в частности, при использовании постобработки модельных расчетов каждого загрязняющего вещества. В табл. 3 приводится пример показателей качества модельного прогноза $\mathrm{NO}_{2}$, полученных при тестировании XTM CHIMERE в холодный период. Здесь показаны усредненные по станциям результаты, свидетельствующие о высокой точности модельного прогноза. Но одной из важнейших задач верификации является выявление наличия систематических погрешностей и установление пространственно-временных особенностей модельных погрешностей. К примеру, установлено, что на большинстве станций городского типа величина ошибки модельного про-

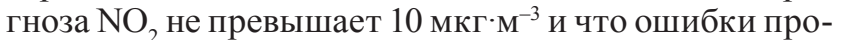
гноза на примагистральных станциях на 5-10 мкг· ${ }^{-3}$ больше, чем на городских станциях.

Особые требования предъявляются к модельным прогнозам в периоды наступления НМУ. Как показывает опыт применения численных расчетов, для повышения надежности прогноза концентраций в таких условиях эффективными оказываются для одних веществ (например, приземного озона) ансамблирование прогнозов двух ХТМ, для других загрязнений (к примеру, $\mathrm{CO}, \mathrm{NO}_{x}$ ) - статистическая коррекция с учетом типа МПЗ [14, 22].

Следует отметить, что из-за многофакторности формирования аэрозольных эпизодов $\left(\mathrm{PM}_{10}\right)$ успешность их прогноза с помощью ХТМ пока еще нужда- ется в синоптической интерпретации. В настоящее время усилия авторов направлены на разработку такой методики. По результатам верификации выявлено, что ошибки модельных расчетов сравнимы с погрешностями статистических методов расчета концентраций загрязняющих веществ в большом городе, а иногда и превосходят их.

\section{Заключение}

Обобщенные данные о влиянии воздушных загрязнений на здоровье и экологически обусловленные заболевания как следствие высокой техногенной нагрузки на урбанизированной территории подтверждают практическую важность мониторинга качества воздуха. Наблюдения за содержанием газоаэрозольного состава атмосферы и прогнозирование метеорологических параметров и концентраций загрязняющих веществ являются основой для прогнозирования ситуаций, связанных с повышением уровня загрязнения в неблагоприятных для очищения воздуха метеорологических условиях.

По данным регулярных наблюдений в сети «Мосэкомониторинг» за содержанием малых газовых составляющих и твердых частиц (размером менее 10 мкм) установлены основные закономерности изменчивости концентраций загрязняющих веществ, обусловленные крупномасштабными атмосферными процессами и локальными метеорологическими условиями в Московском регионе. Использование предложенного комплексного метеорологического параметра загрязнения (МПЗ) позволяет прогнозировать на 2-3 суток вперед неблагоприятные метеорологические условия (НМУ) с сопутствующим по-

Статистические характеристики наблюдавшихся (obs) и модельных (calc) концентраций

Табл. 3 $\mathrm{NO}_{2}\left(\right.$ мкг・ $\left.\mathbf{M}^{-3}\right)$, усредненных по станциям.

XTM WRF-CHIMERE. Холодный период.

(BIAS, RMS, ABS - средняя, средняя квадратическая и абсолютная ошибки)

\begin{tabular}{|c|l|c|c|c|c|c|}
\hline $\begin{array}{c}\text { Количество } \\
\text { дней }\end{array}$ & \multicolumn{1}{|c|}{ Характеристика } & obs & calc & BIAS & RMS & ABS \\
\hline \multirow{3}{*}{1867} & Максимум за сутки & 74,1 & 65,5 & $-8,6$ & 34,7 & 25,9 \\
\cline { 2 - 8 } & Среднее за сутки & 49,3 & 43,8 & $-5,5$ & 21,7 & 17,6 \\
\cline { 2 - 8 } & Среднее за 8 часов & 60,6 & 56,9 & $-3,7$ & 28,5 & 21,9 \\
\hline
\end{tabular}


вышением уровня загрязнения. Практической целью прогнозирования НМУ является информирование населения, властных структур, крупных хозяйствующих субъектов о неблагоприятных внешних воздействиях на здоровье для адаптации к ним за счет реализации предупреждающих мер.

В отсутствии сетевых (регулярных) наблюдений за приземным озоном $\left(\mathrm{O}_{3}\right)$ и твердыми взвешенными частицами $\left(\mathrm{PM}_{10}\right)$ в нашей стране результаты проведенных исследований по наблюдениям в Московском регионе не только представляют ценность для регионального мониторинга, но и указывают на необходимость расширения географии регулярных наблюдений и прогнозирования этих показателей качества воздуха.
В определенной мере численные модели загрязнения с учетом переноса и трансформации веществ (XТМ) могут обеспечить мониторинг качества воздуха на больших территориях; но эффективность применения прогностических методов зависит от погрешностей модельных расчетов. Результаты проведенной в Гидрометцентре России верификации ХТМ на данных непрерывных измерений концентраций различных загрязняющих веществ указывают на необходимость применения постобработки модельных расчетов, одним из способов которой является применение статистической коррекции для разных типов атмосферных процессов и локальных метеорологических условий.

Работа выполнена частично при поддержке проекта РФФИ № 14-05-00481_a.

\section{Литература}

1. Арефьев В.Н., Кашин Ф.В., Милехин Л.И. и соавт. Концентрация приземного озона в Обнинске в 2004-2010 гг. // Известия РАН. Физика атмосферы и океана. - 2013. - Т. 49. - С. 74-84.

2. Аршинова В.Г., Белан Б.Д., Рассказчикова T.M. и соавт. Влияние города Томска на химический и дисперсионный состав атмосферного аэрозоля в приземном слое // Оптика атмосферы и океана. - 2008. - Т. 21. - С. 486-491.

3. Белан Д.Б. Тропосферный озон. Содержание озона в тропосфере. Механизмы и факторы, его определяющие // Оптика атмосферы и океана. - 2008. - Т. 21. - С. 600-618.

4. Вильфанд Р.М., Ривин Г.С., Розинкина И.А. Система COSMO-RU негидростатического мезомасштабного краткосрочного прогноза погоды Гидрометцентра России: первый этап реализации и развития // Метеорология и гидрология. - 2010. - № 8. - С. 5-20.

5. Воздействие взвешенных частиц на здоровье. Рекомендации в отношении политики для стран Восточной Европы, Кавказа и Центральной Азии // Всемирная организация здравоохранения. Европейское региональное бюро. 2013. - C. 14 (www.euro.who.int).

6. Глазкова А.А., Кузнеиова И.Н., Шальгина И.Ю. и соавт. Суточный ход концентрации аэрозоля $\left(\mathrm{PM}_{10}\right)$ летом в Московском регионе // Оптика атмосферы и океана. - 2012. - Т. 25. C. 495-500.

7. Глебова И.С. Оценка комфортности и привлекательности жизнедеятельности в городе (на примере г. Казани) // Современные проблемы науки и образования. - 2013. - № 5 (www. science-education.ru/111-10020).

8. Горчаков Г.И., Семутникова Е.Г., Зоткин E.B. и соавт. Вариации газовых компонент загрязнения в воздушном бассейне г. Москвы // Изв. РАН. Физика атмосферы и океана. - 2006. - Т. 42. - С. 176-190.

9. Горчаков Г.И., Аношин Б.А., Семутникова E.Г. Статистический анализ вариаций массовой концентрации грубодисперсного аэрозоля в г. Москве // Оптика атмосферы и океана. - 2007. - Т. 20. - С. 501-505.

10. Горчаков Г.И., Семутникова Е.Г., Карпов A.B. и соавт. Недельный цикл загрязнения воздуха в г. Москве: количественные характеристики и уточнение методики статистического прогноза концентраций примесей // Оптика атмосферы и океана. - 2010. - Т. 23. - С. 784-792.

11. Доклад о состоянии окружающей среды в городе Москве в 2012 г. - М. : Мосэкомониторинг, 2013. - $180 \mathrm{c}$.

12. Еланский Н.Ф., Локощченко М.А., Беликов И.Б. и соавт. Закономерности изменчивости концентраций малых газовых составляющих в приземном воздухе г. Москвы // Известия РАН. Физика атмосферы и океана. 2007. - T. 43. - С. 219-231.

13. Еланский Н.Ф., Мохов И.И., Беликов И.Б. и соавт. Газовые примеси в атмосфере над Москвой летом 2010 г. // Изв. РАН. Физика атмосферы и океана. - 2011. - Т. 47. - С. 729-743.

14. Зарипов Р.Б., Коновалов И.Б., Кузнецова И.Н. и соавт. Использование моделей WRF ARW и CHIMERE для численного прогноза концентрации приземного озона // Метеорология и гидрология. - 2011. - № 4. - С. 48-60.

15. Звягинцев А.М., Беликов И.Б., Еланский Н.Ф. и соавт. Статистическое моделирование максимальных суточных концентраций приземного озона // Оптика атмосферы и океана. -2010 . - Т. 23. № 2. - С. 1-9.

16. Звягиниев A.M. Статистическое прогнозирование концентраций приземного озона в г. Москве // Метеорология и гидрология. 2008. - № 8. - C. 49-59.

17. Звягинцев А.М., Какаджанова Г., Кручениикий Г.М. и соавт. Периодическая изменчивость приземной концентрации озона в западной и центральной Европе по данным наблюдений // Метеорология и гидрология. 2008. - № 3. - С. 38-47. 
18. Звягиниев А.М., Блюм О.Б., Глазкова А.А. и соавт. Загрязнение воздуха на Европейской части России и в Украине в условиях жаркого лета 2010 года // Известия РАН. Физика атмосферы и океана. - 2011. - Т. 47. - С. 757-766.

19. Звягинцев А.М., Кузнецова И.Н., Тарасова O.A. и соавт. Изменчивость концентраций основных загрязнителей воздуха в Лондоне // Оптика атмосферы и океана. - 2014. - Т. 27. C. 424-434.

20. Коновалов И.Б., Еланский Н.Ф., Звягинцеев A.M. и соавт. Валидация химическотранспортной модели нижней атмосферы Центрально-Европейского региона России с использованием данных наземных и спутниковых измерений // Метеорология и гидрология. - 2009. - № 4. - С. 65-74.

21. Кузнеиова И.Н., Нахаев М.И., Шальгина И.Ю. и соавт. Метеорологические предпосылки формирования зимних эпизодов высокого загрязнения воздуха в г. Москва // Метеорология и гидрология. - 2008. - № 3. - С. 48-59.

22. Кузнецова И.Н., Зарипов Р.Б., Коновалов И.Б. и соавт. Вычислительный комплекс «модель атмосферы - химическая транспортная модель» как модуль системы оценки качества воздуха // Оптика атмосферы и океана. 2010. - T. 23. - № 6. - C. 485-492.

23. Кузнецова И.Н., Звягинцев А.М., Семутникова Е.Г. Экологические последствия погодных аномалий летом 2010 года // Анализ условий аномальной погоды на территории России летом 2010 года: сборник докладов совместного заседания Президиума Научно-технического совета Росгидромета и Научного совета РАН «Исследования по теории климата Земли» / Под ред. Н.П. Шакиной. - М. : Росгидромет, РАН, 2011. - С. 59-64.

24. Кузнецьова И.Н., Глазкова А.А., Шальгина И.Ю. и соавт. Сезонная и суточная изменчивость концентраций взвешенных частиц в приземном воздухе жилых районов Москвы // Оптика атмосферы и океана. - 2014. - Т. 27. C. 473-482.

25. Кузнецова И.Н., Кадыгров Е.Н., Миллер Е.А. и соавт. Характеристики температуры в нижнем 600-метровом слое по данным дистанционных измерений приборами МТП-5 // Оптика атмосферы и океана. - 2012. - Т. 25. - С. 877-883.

26. Кузнеиова И.Н. Влияние метеорологических условий на содержание $\mathrm{PM}_{10}$ и $\mathrm{CO}$ в летних эпизодах 2010 года // Физика атмосферы и океана. - 2012. - Т. 48. - С. 566-577.

27. Кузнецова И.Н., Коновалов И.Б., Глазкова A.A. и соавт. Наблюдаемая и рассчитанная изменчивость концентрации взвешенного вещества $\mathrm{PM}_{10}$ в Москве и Зеленограде // Метеорология и гидрология. - 2011. - № 3. - С. 48-60.

28. Кузнеиова И.Н., Шальгина И.Ю., Нахаев М.И. и соавт. Неблагоприятные для качества воздуха метеорологические факторы // Труды Гидрометцентра России. - 2014. - Вып. 351. С. $154-172$.

29. Лапченко В.А., Звягинцев А.М. Приземный озон в Крыму // Пространство и Время. 2014. - № 2(16). - С. 254-257.
30. Матвеев Л.Т. Влияние большого города на метеорологический режим // Изв. РАН. Сер. геогр. - 2007. - № 4. - С. 97-102.

31. Ревокатова А.П., Суркова Г.В., Кирсанов $A . A$. и соавт. Прогноз загрязнения атмосферы Московского региона с помощью модели COSMO-ART // Вестник МГУ, сер. геогр. 2012. - № 4. - C. 25-32.

32. Рубинштейн К.Г., Гинзбург А.С. Оценка изменения температуры воздуха и количества осадков в крупных городах (на примере Москвы и Нью-Йорка) // Метеорология и гидрология. - 2003. - № 2. - С. 29-38.

33. Сонькин Л.Р. Синоптико-статистический анализ и краткосрочный прогноз загрязнения атмосферы. - Л. : Гидрометеоиздат, 1991. - 223 с.

34. Суркова Г.В., Блинов Д.В., Кирсанов А.А. и соавт. Моделирование распространения шлейфов воздушных загрязнений от очагов лесных пожаров с использованием химико-транспортной модели COSMO-Ru7-ART // Оптика атмосферы и океана. - 2014. - Т. 27. - C. 75-81.

35. Ткачук C.B. Обзор индексов степени комфортности погодных условий и их связь с показателями смертности // Труды Гидрометцентра России. - 2012. - Вып. 347. - С. 223-245.

36. Чубарова Н.Е., Горбаренко Е.В., Незваль Е.И. и соавт. Аэрозольные и радиационные характеристики атмосферы во время лесных и торфяных пожаров в 1972, 2002 и 2010 гг. в Подмосковье // Изв. РАН. Физика атмосферы и океана. - 2011. - Т. 47. - С. 774-789.

37. Шакина Н.П., Иванова А.Р., Кузнеиова И.Н. Волны холода и их проявление в озонометрических данных кисловодской высокогорной научной станции // Изв. РАН. Физика атмосферы и океана. - 2004. - Т. 40. C. $485-500$.

38. Шальгина И.Ю., Кузнеияова И.Н., Нахаев М.И. и соавт. О прогнозировании приземного озона в большом городе (на примере Москвы) // Оптика атмосферы и океана. - 2007. - Т. 20. C. $651-658$.

39. Air pollution in Europe 1990-2004 // European Environment Agency Report. - 2007. No. 2. -84 p.

40. Avnery Sh., Mauzerall D.L., Liu J. et al. Global crop yield reductions due to surface ozone exposure: 2. Year 2030 potential crop production losses and economic damage under two scenarios of $\mathrm{O}_{3}$ pollution // Atmos. Environ. - 2011. Vol. 45. - P. 2297-2309.

41. Despres V.R., Huffman J.A., Burrows S.M. et al. Primary biological aerosol particles in the atmosphere: A Review // Tellus B. - 2012. - Vol. 64, 15598. DOI: 10.3402/tellusb.v64i0.15598.

42. EEA 2010. The European environment. State and outlook 2010. Synthesis. - Copenhagen : European Environment Agency, 2010. - 228 p.

43. Haagen-Smit A.J. A lesson from the smog capital of the world // Proc. Natl. Acad. Sci. U.S.A. - 1970. - Vol. 67. - P. 887-897.

44. Gorchakov G., Semoutnikova E., Karpov $A$. et al. Air Pollution in Moscow Megacity // Advanced Topics in Environmental Health and Air Pollution Case Studies. Intech. -2011. - P. 211-236. 
45. Ghude S.D., Jena C., Chate D.M. et al. Reductions in India's crop yield due to ozone // Geophys. Res. Lett. - 2014. - Vol. 41. - P. 5685-5691.

46. Guerreiro C.B.B., Foltescu V., de Leeuw F. Air quality status and trends in Europe // Atmos. Environ. - 2014. - Vol. 91. - P. 376-384.

47. Fuhrer Jü. Ozone risk for crops and pastures in present and future climates (review) // Naturwissenschaften. - 2009. - Vol. 96. - P. 173-194.

48. Kallistratova M.A., Kouznetsov R.D. Lowlevel jets in the Moscow Region in summer and winter observed with a Sodar Network // Boundary-Layer Meteorol. - 2012. - Vol. 143. P. 159-175. DOI 10.1007/s10546-011-9639-8.

49. Pollack I.B., Ryerson T.B., Trainer M. et al. Trends in ozone, its precursors, and related secondary oxidation products in Los Angeles, California: A synthesis of measurements from 1960 to 2010 // J. Geophys. Res. - 2013. - Vol. 118. - P. 5893-5911. 50. Sofiev M., Prank M., Finardi S., et al. Influence of Regional Scale Emissions on Megacity Air Quality // MEGAPOLI Deliverable D5.5. / Sofiev M., Prank M., Baklanov A. (Eds.) - MEGAPOLI Scientific Report 11-12. - Helsinki-Cpenhagen, 2011. - 60 p. (http://megapoli.dmi.dk/publ/MEGAPOLI sr11-12.pdf)

51. Tarasova O.A., Brenninkmeijer C.A., Joeckel $P$. et al. A climatology of surface ozone in the extra tropics: cluster analysis of observations and model results // Atmos. Chem. Phys. - 2007. Vol. 7. - P. 6099-6117.

52. Sillman $S$. The relation between ozone, $\mathrm{NO}_{x}$ and hydrocarbons in urban and polluted rural environments // Atmos. Environ. - 1999. - Vol. 33. P. $1821-1845$.

53. Vogel B., Vogel H., Baumner D. et al. The comprehensive model system COSMO-ART - Radiative impact of aerosol on the state of the atmosphere on the regional scale // Atmos. Chem. Phys. - 2009. - Vol. 9. - P. 8661-8680.

54. Wild $O$. Modelling the global tropospheric ozone budget: exploring the variability in current models // Atmos. Chem. Phys. - 2007. - Vol. 7. P. $2643-2660$.

55. WHO 2005. Air Quality Guidelines: Global Update 2005. Particulate matter, Ozone, Nitrogen Dioxide and Sulfur Dioxide. - WHO, 2006. $484 \mathrm{p}$.

56. WMO/IGAC. GAW Report No. 205. Impacts of Megacities on Air Pollution and Climate. - Geneva, WMO, 2012. - $314 \mathrm{p}$

57. Wu S., Mickley L.J., Jacob D.J. et al. Why are there large differences between models in global budgets of tropospheric ozone? // J. Geophys. Res. - 2007. - Vol. 112. - P. 2156-2202.

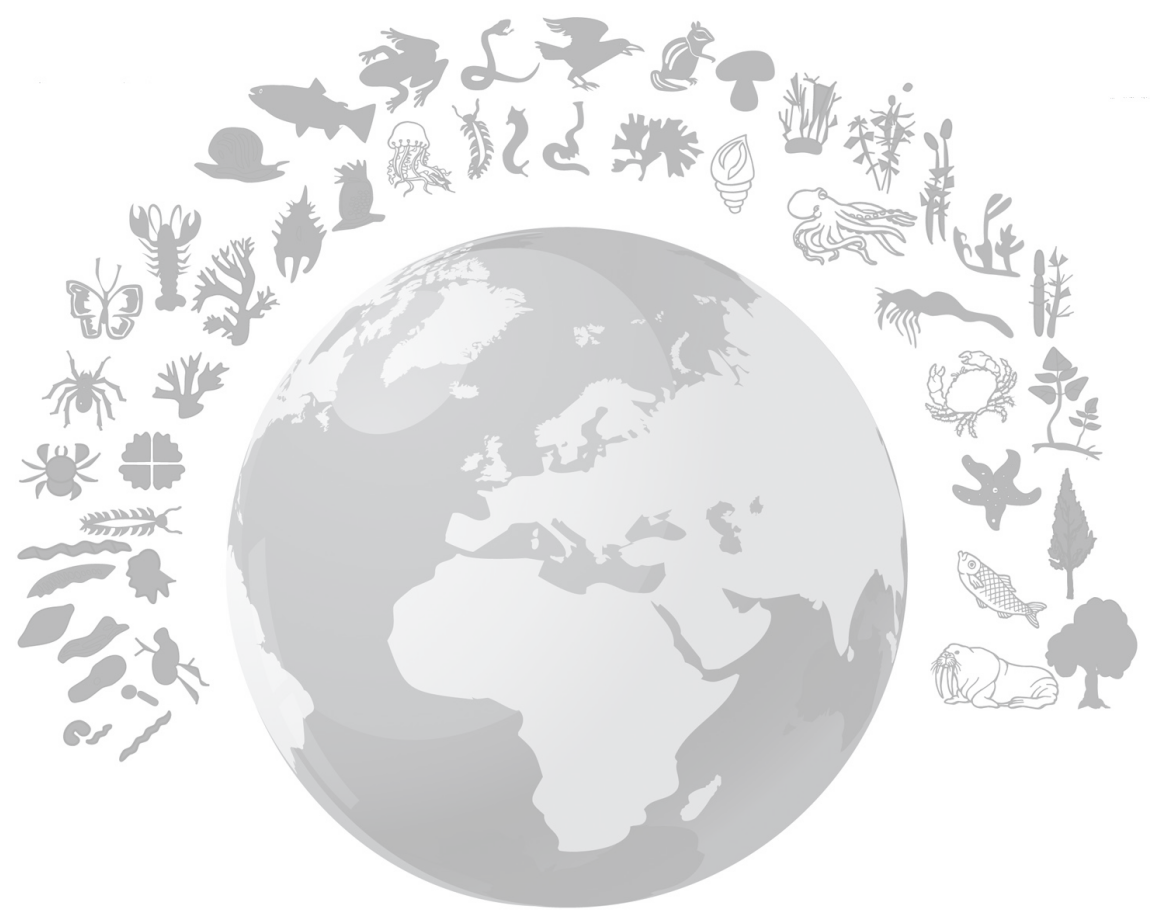

